\title{
Análise da cobertura vegetal em duna semifixa dez anos após a aplicação de técnicas de restauração no Parque Municipal das Dunas da Lagoa da Conceição, Florianópolis, Santa Catarina
}

\author{
Nina Rosa Zanin Zanella ${ }^{1}$ \\ Marisa Prudencio ${ }^{2}$ \\ Tânia Tarabini Castellani ${ }^{1 *}$ \\ ${ }^{1}$ Departamento de Ecologia e Zoologia, Centro de Ciências Biológicas \\ Universidade Federal de Santa Catarina \\ Caixa Postal 476, CEP 88040-900, Florianópolis - SC, Brasil \\ ${ }^{2}$ ACEPSJ - Associação Ambientalista Comunitária Espiritualista Patriarca São José \\ Florianópolis - SC, Brasil \\ *Autor para correspondência \\ ttcastel@ccb.ufsc.br
}

Submetido em 30/10/2009

Aceito para publicação em 18/06/2010

\section{Resumo}

A cobertura vegetal de uma duna semifixa foi avaliada dez anos após a implantação de um projeto de restauração, que utilizou técnicas de semeadura, plantio e transposição de mudas, com irrigação nos primeiros meses após a implantação. Em dez anos, o setor de topo da duna recuperada apresentou cobertura vegetal esparsa (53\%), porém superior à área controle (34\%), ambas com fisionomia herbácea/subarbustiva, com predomínio de Panicum racemosum. O setor em declive, com fisionomia arbustiva, mostrou alta cobertura vegetal (90\%), similar à área controle (100\%), com predomínio de Dodonaea viscosa no setor restaurado. O sucesso de estabelecimento das mudas de plantas arbustivas e arbóreas na área de topo determinou em parte a maior riqueza deste setor e uma baixa similaridade com a área controle. A área de declive apresentou elevada dominância de $D$. viscosa, a menor riqueza específica e pequena similaridade com a área controle, com dominância de pelo menos três espécies arbustivas. Plantas introduzidas por semeadura e transposição de mudas de áreas adjacentes tiveram sucesso de estabelecimento e contribuíram para a similaridade florística. As mudas de espécies arbustivas e arbóreas mostraram sucesso de estabelecimento apenas em um setor de dunas, mas geraram diferenças na composição específica com as áreas do entorno, já que figuram como elementos de estágios sucessionais mais avançados.

Unitermos: dunas, fitossociologia, restauração, restinga

\section{Abstract}

Vegetation development in a sand dune ten years after restoration, Parque Municipal das Dunas da Lagoa da Conceição, Florianópolis, Santa Catarina. The vegetation cover of a sand dune was surveyed ten years after the improvement of a restoration project that utilized seed sowing, seedling planting and seedling transplantation from an adjacent area with watering in the first months. On the upper part of the restored dune, the vegetation was sparse (53\%) but more developed than that of the adjacent control area (34\%), both presenting herbaceous/subshrub physiognomy with predominance of Panicum racemosum. On the slope of the restored 
dune, a shrub vegetation developed, presenting a percentage cover (90\%) similar to that of the control area $(100 \%)$. Dodonaea viscosa was the dominant species on this restored face. The establishment of arboreal and shrub species seedlings on the upper dune was good. In part, this improved the species richness, but contributed to dissimilarity between this area and the control site. A lower species richness was presented on the slope and the similarity to the control area was even lower. Plants introduced by sowing and seedling transplantation showed success and contributed to the similarity with the adjacent vegetation. Seedlings of arboreal and shrub plants survived on the upper dune. These species are represented in a more developed stage of succession, differing from the adjacent control area.

Key words: dune, phytosociology, "restinga", restoration

\section{Introdução}

Registros de atividades humanas nas restingas brasileiras datam de cerca de 8000 anos (Zamith e Scarano, 2006), mas é a partir da colonização européia que estas formações passam a ser progressivamente destruídas, estando próximas dos primeiros povoados e posteriormente de grandes expansões urbanas (Falkenberg, 1999; Zamith e Scarano, 2006). Desta forma, ações para a conservação das áreas remanescentes e restauração de áreas alteradas são necessárias para a preservação desses ecossistemas (Zamith e Scarano, 2006).

Técnicas voltadas à restauração de restingas brasileiras vêm sendo aplicadas após diferentes tipos de interferência antrópica, dentre estes, construção viária (Freire, 1983), mineração (Miranda et al., 1997; Cunha et al., 2003), resgates arqueológicos (Scherer-Widmer, 2001), loteamentos e ocupação ilegal (Zamith e Scarano, 2006) e remoção de plantios com espécies florestais exóticas (Bechara, 2006). Estas alterações podem gerar dunas desnudas e móveis, sendo necessária uma rápida fixação, evitando seus deslocamentos para áreas residenciais e vias de acesso, assim como para demais áreas vegetadas (Seeliger et al., 2000; Dewhurst, 2001; Seeliger, 2003). Para a retenção de sedimento em dunas, além do plantio de espécies de rápido crescimento (Freire, 1983; Cunha et al., 2003), barreiras físicas como detritos vegetais, cercas de madeira, entre outras, são aplicadas para contenção do vento e manutenção de umidade no substrato (Nordstrom, 2000; Scherer-Widmer, 2001).

Perturbações mais intensas podem requerer a recuperação de feições geomorfológicas e de condições edáficas para iniciar o restabelecimento da vegetação (Nordstrom, 2000). Projetos de restauração após mineração, por exemplo, implementam ações que envolvem plantio de espécies de rápido crescimento, sendo fundamental a adição de solo de áreas adjacentes de restinga, para incrementar o aporte de matéria orgânica, nutrientes, propágulos do banco de sementes, microrganismos simbiônticos e decompositores (Miranda et al., 1997; Cunha et al., 2003). Técnicas de nucleação (Reis et al., 2003) adotadas para restauração de restinga após remoção de plantio de Pinus spp. (Bechara, 2006) também utilizam a transposição de solo de áreas remanescentes e o plantio de mudas nativas em pequenos grupos, visando a expansão desses núcleos. A semeadura direta de espécies herbáceas e arbustivas nativas, o estabelecimento de poleiros e a deposição de núcleos de galharias no solo também são adotados, sendo os dois últimos procedimentos voltados a atrair e abrigar a fauna, promovendo um aumento de diversidade e interações bióticas na comunidade (Bechara, 2003; 2006).

Zamith e Scarano (2006) salientam que para o sucesso da restauração de áreas de restinga pode ser necessária a retirada de espécies exóticas para o posterior plantio de mudas de plantas herbáceas e arbóreas nativas. Os autores sugerem que o plantio direto de mudas é a melhor estratégia para esses ambientes, uma vez que o estabelecimento de plântulas a partir de sementes é muito difícil no substrato arenoso da restinga, pobre em nutrientes, com alta insolação e baixa retenção hídrica. No entanto, muitos projetos de restauração parecem envolver técnicas que promovem tanto o aporte de sementes como o plantio por mudas (Miranda et al., 1997; Bechara, 2006), podendo estas derivar de sementes ou de fragmentos de estolão e rizoma de espécies que possuem tais estruturas (Freire, 1983; Scherer-Widmer, 2001; Gomes-Neto et al., 2004). 
Em decorrência da retirada de vegetação que acarretou a mobilidade de duna em área limítrofe ao Parque Municipal das Dunas da Lagoa da Conceição, em Florianópolis, Prudencio (1999a) realizou um projeto para restaurar a vegetação fixadora de duna, uma vez que residências estavam sendo invadidas e soterradas por areia. Foram aplicadas técnicas de semeadura, plantio direto de mudas de viveiro, além de mudas transpostas de áreas adjacentes.

Assumindo que os projetos de restauração visam desencadear o processo natural de sucessão vegetacional, espera-se que, em longo prazo, a comunidade se aproxime de uma fisionomia e composição florística característica na área. Neste contexto, o presente estudo visa avaliar a recomposição da cobertura vegetal em uma duna semifixa dez anos após a aplicação de técnicas de restauração e pretende abordar: a) como a área restaurada assemelha-se estruturalmente a áreas adjacentes não alteradas e b) qual a contribuição exercida pelas espécies introduzidas e daquelas que colonizaram de forma espontânea o trecho em recuperação.

\section{Material e Métodos}

\section{Área de estudo}

O Parque Municipal das Dunas da Lagoa da Conceição está situado próximo à praia da Joaquina, no leste da Ilha de Santa Catarina, entre as latitudes $27^{\circ} 36^{\prime} 24^{\prime \prime}-27^{\circ} 38^{\prime} 39^{\prime \prime}$ 'S e longitudes $48^{\circ} 26^{\prime} 49^{\prime \prime}$ $48^{\circ} 28^{\prime} 5^{\prime \prime} \mathrm{W}$, apresentando uma área total de $563 \mathrm{ha}$. Nesta região o tipo climático é classificado como Cfa de Köppen, mesotérmico úmido, sem estação seca definida, verões quentes e chuvas bem distribuídas ao longo do ano, com precipitação média anual de $1.521 \mathrm{~mm}$. A umidade relativa do ar é de $82,1 \%$ em média ao ano e as temperaturas médias podem variar entre $15,5^{\circ} \mathrm{C}$ e $26^{\circ} \mathrm{C}$ no decorrer dos meses. Os ventos predominantes são oriundos dos quadrantes norte e sul (Santos et al., 1997).

O Parque foi criado em 1988 pelo Decreto Municipal $n^{0} 231$ (CECCA, 1997) e engloba o principal complexo de dunas móveis e semifixas da ilha (Bresolin, 1979). Aárea do presente estudo situa-se num cômoro (crista) de duna semifixa, no limite norte do cordão de dunas móveis do Parque. Neste local, foi implantado em 1999 um projeto para recompor a vegetação fixadora de duna (Prudencio, 1999a), visando restabelecer a estabilidade desse segmento de duna, alterado pela remoção da vegetação original. Com base em um levantamento florístico prévio e em bibliografia (Bresolin, 1979; Falkenberg, 1999) se verificou que entre as plantas herbáceas pioneiras encontradas próximas ao local destacavam-se: Panicum racemosum, Diodia radula e Senecio platensis. Em sua face norte observavase a ocorrência de um estrato arbustivo com presença de Alchornea triplinervia, Schinus terebinthifolius, Vitex megapotamica, Clusia criuva, Gomidesia palustris, Guapira opposita, Gaylussacia brasiliensis, Lithrea brasiliensis e Dodonaea viscosa. Também se verificava a presença de Pennisetum purpureum, uma gramínea exótica invasora introduzida por ação humana (Prudencio, 1999a).

\section{Síntese do projeto implantado em 1999}

Com a remoção da vegetação, houve desestabilização da duna e a formação de um pequeno corredor de deslizamento de areia (20m de largura), com intenso deslocamento em direção norte, devido à ação dos ventos do quadrante sul. Isto acarretou o soterramento parcial de uma casa adjacente à área e ameaçava, em curto prazo, outra residência. A primeira ação realizada antes do plantio de mudas foi a montagem de uma barreira provisória de bambu, com $1,5 \mathrm{~m}$ de altura e de $52,2 \mathrm{~m}$ de comprimento, para a proteção inicial das mudas da ação dos ventos e para conter momentaneamente o deslocamento da areia (Figura 1). Foi instalado um sistema de irrigação (Figura 2), acionado duas vezes por dia (pela manhã e final da tarde), durante os primeiros quatro meses, para garantir o sucesso do plantio. Este sistema foi instalado com a implantação de uma ponteira e auxílio de motobomba. A área total de plantio de mudas foi de $800 \mathrm{~m}^{2}$ divididos em dois módulos: Área 1 com $600 \mathrm{~m}^{2}$, área do topo da duna, e Área $2 \mathrm{com} 200 \mathrm{~m}^{2}$, situada na área de declive da duna (Prudêncio, 1999b). 


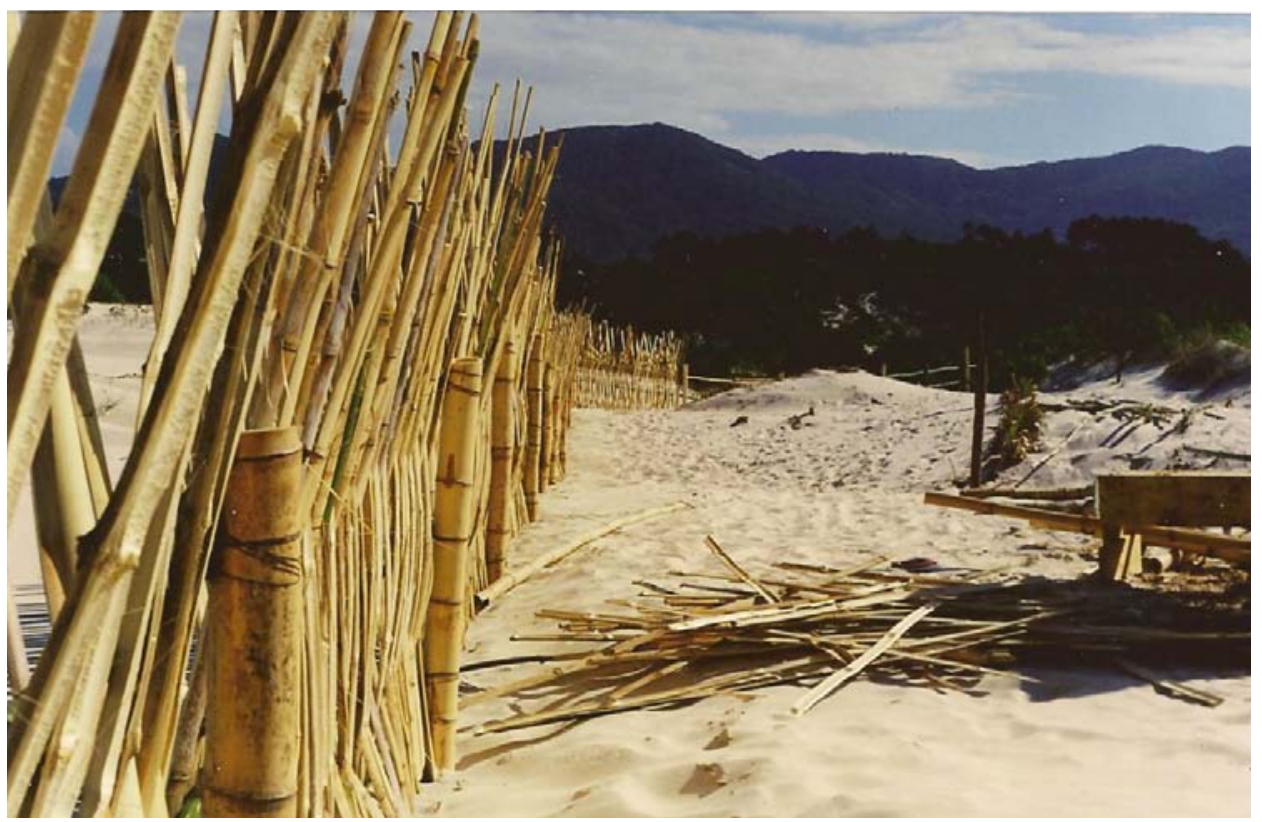

FIGURA 1: Cerca de bambu com 1,5m de altura e 52,2m de comprimento instalada antes do plantio de mudas e da semeadura na área a ser restaurada. Parque Municipal das Dunas da Lagoa da Conceição, Florianópolis, SC.

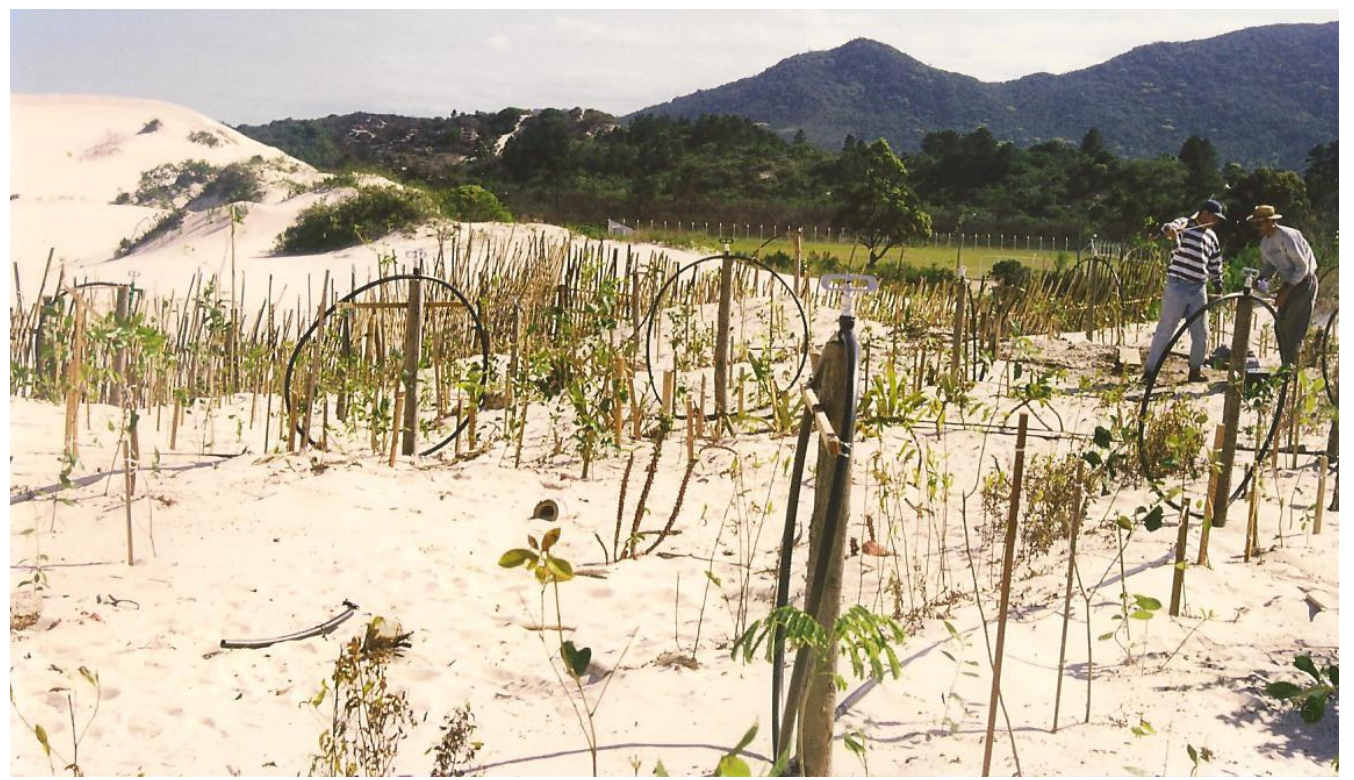

FIGURA 2: Sistema de irrigação implantado na área em restauração evidenciando mudas com cerca de um mês após o plantio (outubro de 1999). Parque Municipal das Dunas da Lagoa da Conceição, Florianópolis, SC.

Foram aplicadas técnicas de semeadura e plantio direto de mudas de viveiro, além de transposição de mudas de áreas adjacentes. Primeiro foi feito o plantio das mudas provindas de viveiro, pois este envolve um pisoteio mais intenso na área. As mudas eram de espécies nativas de estrato arbustivo e arbóreo de restinga (Tabela 1), com exceção de Inga uruguensis, totalizando 846 mudas. Utilizaram-se camas de $30 \mathrm{~cm}$ de largura por $50 \mathrm{~cm}$ de profundidade para esse plantio, com espaçamento de $0,5 \times 0,5 \mathrm{~m}$ entre as plantas. Foi usada adubação orgânica nas covas, misturadas à terra argilosa, visando suprir as necessidades das plantas nos primeiros meses. Posteriormente, foi feita a semeadura e a transposição de mudas em linhas intercaladas com o plantio das mudas, também com adubação orgânica. Foi feita a semeadura de Panicum racemosum e Dodonaea 
viscosa, plantio de fragmentos de espécies herbáceas como Diodia radula e Senecio platensis e transposição de plântulas dos arbustos pioneiros D. viscosa e Baccharis sp., todas remanejadas de áreas adjacentes. Foi construída uma cerca na base nordeste, na área de declive, com o objetivo de barrar o acesso de transeuntes, além de uma placa sinalizando a área em recuperação (Prudêncio, 1999a).

TABELA 1: Espécies provenientes de viveiro plantadas na área do projeto de recomposição da vegetação. Parque Municipal das Dunas da Lagoa da Conceição, Florianópolis, SC. (Adaptado de Prudencio, 1999a).

\begin{tabular}{|c|c|c|}
\hline Família & Nome Científico & Nome Popular \\
\hline Anacardiaceae & $\begin{array}{l}\text { Lithrea brasiliensis } \\
\text { Marchand } \\
\text { Schinus terebinthifolius } \\
\text { Raddi }\end{array}$ & $\begin{array}{l}\text { Aroeira-branca } \\
\text { Aroeira-verme- } \\
\text { lha }\end{array}$ \\
\hline Clusiaceae & $\begin{array}{l}\text { Calophyllum brasiliense } \\
\text { Cambess. }\end{array}$ & Olandi \\
\hline Ericaceae & $\begin{array}{l}\text { Gaylussacia brasiliensis } \\
\text { (Spreng.) Meisn. }\end{array}$ & Camarinha \\
\hline Fabaceae & $\begin{array}{l}\text { Enterolobium contortisi- } \\
\text { liquum (Vell.) Morong } \\
\text { Inga uruguensis Hook. } \\
\text { \& Arn. }\end{array}$ & Ingá-banana \\
\hline Lauraceae & $\begin{array}{l}\text { Ocotea pulchella (Nees) } \\
\text { Mez }\end{array}$ & $\begin{array}{l}\text { Canelinha-do- } \\
\text {-brejo }\end{array}$ \\
\hline Myrsinaceae & $\begin{array}{l}\text { Myrsine parvifolia A. } \\
\text { DC. }\end{array}$ & $\begin{array}{l}\text { Capororoca-do- } \\
\text {-brejo }\end{array}$ \\
\hline Myrtaceae & $\begin{array}{l}\text { Eugenia umbelliflora } \mathrm{O} . \\
\text { Berg }\end{array}$ & Baguaçu-mirim \\
\hline & $\begin{array}{l}\text { Gomidesia palustris } \\
\text { (DC.) Kausel }\end{array}$ & $\begin{array}{l}\text { Guamirim-da- } \\
\text {-praia }\end{array}$ \\
\hline & $\begin{array}{l}\text { Psidium cattleyanum } \\
\text { Sabine }\end{array}$ & Araçá \\
\hline
\end{tabular}

Após a implantação do projeto, foram feitas quatro vistorias no primeiro mês, uma a cada semana. Nesta data, verificou-se uma taxa de $100 \%$ de sobrevivência das mudas plantadas, demonstrando a eficácia do sistema de irrigação e da proporção de 1:1 de matéria orgânica e terra argilosa. Houve, no entanto, a formação de um cômoro no ângulo NE da área 1 , ocorrendo soterramento de $43 \%$ das mudas neste local. Este cômoro correspondia a menos de $10 \%$ da área 1 e provavelmente decorreu da abertura de um espaço entre a superfície da duna e o anteparo de bambu, derivado da ação dos ventos. Com o estabelecimento de $P$. racemosum, houve uma atenuação do soterramento, devido a sua capacidade de fixar e suportar a deposição de areia (Costa et al., 1991; Cordazzo et al., 2006). Houve boa germinação tanto de $P$. racemosum como de D. viscosa nas duas áreas e as espécies remanejadas, $D$. radula, S. platensis e $D$. viscosa apresentaram boas taxas de sobrevivência e desenvolvimento radicular, demonstrando capacidade de emergir diante do soterramento. Na área 1, topo de duna, com base no método do ponto (Greig-Smith, 1983), avaliou-se uma taxa de cobertura vegetal de $25 \%$ ( $\mathrm{n}=111)$ (Prudêncio, 1999b).

\section{Procedimentos em campo e análise de dados}

De agosto a outubro de 2008, foi avaliada a porcentagem de cobertura vegetal no setor de implantação do projeto e em área adjacente não alterada. Para isto, se aplicou o método do ponto ("point quadract method"), que tem como base que uma superfície é composta de finitos pontos de pequena dimensão. Assim, neste método, rwegistra-se a presença (ou ausência) de uma espécie da comunidade vegetal acima de pontos de superfície e a porcentagem de pontos na qual a espécie ocorre representa sua porcentagem de cobertura (GreigSmith, 1983). Para esta avaliação, utilizou-se um pino de ferro de $5 \mathrm{~mm}$ de diâmetro e $1 \mathrm{~m}$ de altura. Em cada ponto amostral, o pino foi projetado verticalmente sobre a superfície do solo, sendo anotadas todas as espécies por ele interceptadas. Em cada área, os pontos amostrais foram distribuídos de forma regular ao longo de linhas distanciadas $2 \mathrm{~m}$ entre si. Na área de topo, cada linha tinha $20 \mathrm{~m}$ e foram amostrados 20 pontos/ linha, totalizando 400 pontos. Na área de declive, cada linha tinha $10 \mathrm{~m}$, com 10 pontos/linha, totalizando 50 pontos. Da mesma maneira, duas áreas adjacentes foram amostradas, uma de topo de duna e outra em declive. Essas áreas foram designadas neste trabalho como áreas controle. Essas estavam distantes $130 \mathrm{~m}$ da área restaurada, sendo escolhidas com base na similaridade de topografia e orientação geográfica.

Além do cálculo da porcentagem de cobertura de cada espécie $\left(\mathrm{PC}_{\mathrm{i}}\right)$, foi também calculada a 
porcentagem de pontos cobertos por vegetação (isto é, cobertos por pelo menos uma espécie), ora designada como porcentagem de cobertura total $\left(\mathrm{PC}_{\mathrm{t}}\right)$. Para avaliar se a cobertura total $\left(\mathrm{PC}_{\mathrm{t}}\right)$ diferia entre as áreas restauradas e adjacentes realizou-se um teste de $\chi^{2}$ com correção de Yates (Zar, 1999) considerando-se o total de pontos amostrados com e sem vegetação. As áreas restauradas também foram comparadas com as áreas adjacentes por análises de similaridade, índice de Sorensen e porcentagem de similaridade (Krebs, 1999), e análises de diversidade, índice de Simpson e de Equitabilidade (Begon et al., 1986). Foi feito o teste $t$ de Student para verificar se havia diferença significativa entre os índices de diversidade de Simpson (Brower et al., 1998).

Para observar a mobilidade atual da duna, foram colocadas três estacas de PVC em cada área de topo e duas em cada área de declive (restaurada e controle), onde se pôde acompanhar a movimentação da areia ao longo dos meses de estudo. Estas estacas, graduadas em centímetros, tinham $1 \mathrm{~m}$ de altura, sendo que $50 \mathrm{~cm}$ ficavam enterrados e $50 \mathrm{~cm}$ ficavam expostos.

\section{Resultados}

Foram encontradas para todas as áreas (topo e declive; restauradas e adjacentes) 51 espécies distribuídas em 29 famílias (Tabela 2). Das 11 espécies introduzidas por mudas de viveiro, oito (73\%) estavam presentes nas áreas restauradas, sete registradas no topo e três no declive: Calophyllum brasiliense (topo), Enterolobium contortisiliquum (topo), Gomidesia palustris (topo), Inga uruguensis (topo), Lithrea brasiliensis (topo e declive), Ocotea pulchella (declive), Psidium cattleyanum (topo e declive), Schinus terebinthifolius (topo). Apenas $O$. pulchella ocorreu em setor restaurado e também em área adjacente. As demais ocorreram apenas nos trechos revegetados. Das 11 espécies introduzidas por mudas, Eugenia umbelliflora, Myrsine parvifolia e Gaylussacia brasiliensis não sobreviveram (Tabela 2).

Além destas oito espécies, Diodia radula, Dodonaea viscosa, Panicum racemosum e Senecio platensis, que foram semeadas e/ou transpostas de áreas adjacentes, mantiveram-se na área revegetada.
Desta forma, observa-se que pelo menos 14 espécies colonizaram de forma espontânea a área de topo e 14 a área de declive restaurada (Tabela 2).

$\mathrm{Na}$ área de topo restaurada, com $53 \%$ de solo coberto (Tabela 3), as maiores coberturas absolutas foram de Panicum racemosum, Dodonaea viscosa, Alchornea triplinervia e Senecio platensis (Tabela 2). Essa área mostrou maior cobertura vegetal que a área adjacente (Tabela 3$)\left(\chi_{\text {Yates }}^{2}=29,40 ; p=0,0000\right.$; g.l=1), onde $P$. racemosum e $S$. platensis também estiveram entre aquelas de maior cobertura, junto a Ilex theazans e Oxypetalum tomentosum (Tabela 2). A área restaurada em declive apresentou $90 \%$ de solo coberto (Tabela 3), sendo as maiores coberturas de D. viscosa, Melinis minutiflora, Urochloa sp., Diodia radula e $O$. tomentosum (Tabela 2). Essa área teve uma porcentagem de cobertura equivalente à área controle (Tabela 3) $\left(\chi_{\text {Yates }}^{2}=3,40 ; \mathrm{p}=0,07 ; \mathrm{gl}=1\right)$, onde se destacaram Gaylussacia brasiliensis, Vitex megapotamica, Guapira opposita e D. radula (Tabela 2).

Quanto à mobilidade de substrato, na área de topo em restauração houve acréscimo de $3 \mathrm{~cm}$ em duas estacas e decréscimo de $3 \mathrm{~cm}$ em outra. $\mathrm{Na}$ área controle houve acréscimos de $2 \mathrm{~cm}, 1 \mathrm{~cm}$ e decréscimo de $0,5 \mathrm{~cm}$. Na área de declive em restauração não houve mobilidade de areia em uma estaca e acréscimo de $5 \mathrm{~cm}$ em outra. A área em declive controle não apresentou mudanças.

Foi registrada a presença de lixo na área, como se fosse um lugar de despejo clandestino, com presença de roupas, plásticos e latas e também trilhas na área de declive em recuperação. 
TABELA 2: Famílias e espécies ocorrentes nas áreas de estudo restauradas (R) (topo e declive) e áreas controle (C) e as porcentagens de cobertura absoluta das espécies. (M) são espécies que tiveram plantio de mudas de viveiro, (TM) mudas transpostas e (S) semeadura a partir de áreas adjacentes. Parque Municipal das Dunas da Lagoa da Conceição, Florianópolis, SC.

\begin{tabular}{|c|c|c|c|c|c|}
\hline \multirow{2}{*}{ Família } & \multirow{2}{*}{ Espécie } & \multicolumn{2}{|c|}{ Торо\% } & \multicolumn{2}{|c|}{ Declive\% } \\
\hline & & $\mathbf{R}$ & $\mathbf{C}$ & $\mathbf{R}$ & $\mathbf{C}$ \\
\hline Agavaceae & Furcraea foetida (L.) Haw. & - & - & 2,0 & - \\
\hline \multirow[t]{2}{*}{ Anacardiaceae } & Lithrea brasiliensis Marchand ${ }^{(\mathrm{M})}$ & 1,3 & - & 6,0 & - \\
\hline & Schinus terebinthifolius $\operatorname{Raddi}^{(\mathrm{M})}$ & 0,8 & - & - & - \\
\hline Apocynaceae & Oxypetalum tomentosum Wight ex Hook. \& Arn. & 2,5 & 5,3 & 18,0 & 10,0 \\
\hline Aquifoliaceae & Ilex theazans Mart. & - & 5,5 & - & 2,0 \\
\hline \multirow[t]{4}{*}{ Asteraceae } & Eupatorium casarettoi (B. L. Rob.) Steyerm. & - & 0,5 & 8,0 & 6,0 \\
\hline & Mikania involucrata Hook. \& Arn. & - & - & - & 2,0 \\
\hline & Noticastrum malmei Zardini & - & 1,0 & - & 2,0 \\
\hline & Senecio platensis Arechav. ${ }^{(\mathrm{TM})}$ & 6,3 & 3,8 & - & - \\
\hline Boraginaceae & Cordia curassavica (Jacq.) Roem. \& Schult. & - & 0,3 & 2,0 & 4,0 \\
\hline Bromeliaceae & Vriesea friburgensis $\mathrm{Mez}$ & - & - & 4,0 & 4,0 \\
\hline Cannabaceae & Trema micrantha (L.) Blume & 0,3 & - & - & - \\
\hline \multirow[t]{2}{*}{ Clusiaceae } & Calophyllum brasiliense Cambess. ${ }^{(\mathrm{M})}$ & 0,8 & - & - & - \\
\hline & Clusia criuva Cambess. & - & - & - & 4,0 \\
\hline Commelinaceae & Commelina sp. & 1,3 & - & 2,0 & 2,0 \\
\hline Convolvulaceae & Evolvulus glomeratus Nees \& Mart. & - & - & - & 2,0 \\
\hline Ericaceae & Gaylussacia brasiliensis (Spreng.) Meisn. ${ }^{(\mathrm{M})}$ & - & 3,0 & - & 38,0 \\
\hline Euphorbiaceae & Alchornea triplinervia (Spreng.) Müll. Arg. & 8,5 & 0,5 & 4,0 & 2,0 \\
\hline \multirow[t]{5}{*}{ Fabaceae } & Crotalaria pallida Aiton & - & - & - & 6,0 \\
\hline & Desmodium sp. & - & 0,5 & - & - \\
\hline & Enterolobium contortisiliquum (Vell.) Morong ${ }^{(\mathrm{M})}$ & 3,3 & - & - & - \\
\hline & Inga uruguensis Hook. \& Arn. ${ }^{(\mathrm{M})}$ & 2,3 & - & - & - \\
\hline & Mimosa bimucronata (DC.) Kuntze & 3,0 & - & - & - \\
\hline Lamiaceae & Vitex megapotamica (Spreng.) Moldenke & 0,8 & 2,0 & - & 34,0 \\
\hline Lauraceae & Ocotea pulchella $(\mathrm{Nees}) \mathrm{Mez}^{(\mathrm{M})}$ & - & 0,8 & 6,0 & 4,0 \\
\hline Malpighiaceae & Stigmaphyllon ciliatum (Lam.) A. Juss. & - & - & 2,0 & - \\
\hline Melastomataceae & Tibouchina sp. & - & - & - & 4,0 \\
\hline \multirow[t]{3}{*}{ Myrtaceae } & Eugenia catharinae O. Berg & 0,3 & 0,3 & - & 6,0 \\
\hline & Gomidesia palustris (DC.) Kausel ${ }^{(\mathrm{M})}$ & 0,5 & - & - & 2,0 \\
\hline & Psidium cattleyanum Sabine $^{(\mathrm{M})}$ & 0,5 & - & 2,0 & - \\
\hline Nyctaginaceae & Guapira opposita (Vell.) Reitz & 0,3 & 2,3 & - & 26,0 \\
\hline Ochnaceae & Ouratea salicifolia Engl. & - & - & - & 14,0 \\
\hline Orchidaceae & Epidendrum fulgens Brongn. & - & 0,3 & - & 2,0 \\
\hline Pinaceae & Pinus sp. & - & - & 4,0 & - \\
\hline Piperaceae & Peperomia glabella (Sw.). A. Dietr. & - & - & - & 8,0 \\
\hline \multirow[t]{9}{*}{ Poaceae } & Andropogon arenarius Hack. & 0,3 & 0,5 & - & 2,0 \\
\hline & Cynodon maritimus Kunth & - & - & - & 2,0 \\
\hline & Melinis minutiflora P. Beauv. & 2,5 & - & 26,0 & - \\
\hline & Panicum racemosum (P. Beauv.) Spreng. ${ }^{(\mathrm{S})}$ & 18,8 & 8,5 & - & - \\
\hline & Paspalum vaginatum $\mathrm{Sw}$. & 0,5 & - & 2,0 & - \\
\hline & Rhynchelytrum repens (Willd.) C.E. Hubb. & - & 0,3 & - & - \\
\hline & Urochloa sp. & 2,8 & - & 20,0 & 6,0 \\
\hline & Indeterminada 1 & - & - & 4,0 & - \\
\hline & Indeterminada 2 & - & 0,3 & - & - \\
\hline \multirow[t]{2}{*}{ Rubiaceae } & Chiococca alba (L.) Hitchc. & - & 1,0 & - & 8,0 \\
\hline & Diodia radula (Wild. \& Hoffmanns. ex Roem \& Schult.) Cham. \& Schltdl. ${ }^{\mathrm{TM}}$ & 3,3 & 1,3 & 18,0 & 24,0 \\
\hline \multirow[t]{2}{*}{ Sapindaceae } & Dodonaea viscosa Jacq. ${ }^{(\mathrm{S}, \mathrm{TM})}$ & 16,8 & 1,0 & 52,0 & 2,0 \\
\hline & Paullinia trigonia Vell. & 0,3 & - & 2,0 & - \\
\hline Smilacaceae & Smilax campestris Griseb. & - & - & - & 6,0 \\
\hline Verbenaceae & Lantana camara $\mathrm{L}$. & 0,5 & - & - & - \\
\hline
\end{tabular}


TABELA 3: Número de espécies, cobertura vegetal, diversidade e similaridade entre as áreas em recuperação (topo e declive) e respectivas áreas controle. Parque Municipal das Dunas da Lagoa da Conceição, Florianópolis, SC.

\begin{tabular}{|c|c|c|c|c|}
\hline & \multicolumn{2}{|c|}{ Topo } & \multicolumn{2}{|c|}{ Declive } \\
\hline & Restaurada & Controle & Restaurada & Controle \\
\hline $\begin{array}{l}\text { Número de } \\
\text { espécies (S) }\end{array}$ & 25 & 21 & 19 & 29 \\
\hline $\begin{array}{l}\text { Área Coberta } \\
(\%)\end{array}$ & 53 & 34 & 90 & 100 \\
\hline Área Nua (\%) & 47 & 66 & 10 & 0 \\
\hline $\begin{array}{l}\text { Equitabilidade } \\
\text { (E) }\end{array}$ & 0,30 & 0,42 & 0,38 & 0,41 \\
\hline $\begin{array}{l}\text { Diversidade } \\
\text { Simpson (1/D) }\end{array}$ & 7,5 & 8,8 & 7,3 & 11,9 \\
\hline Teste $\mathrm{t}$ & \multicolumn{2}{|c|}{$41,31(\mathrm{P}<0,05)$} & \multicolumn{2}{|c|}{$287,13(\mathrm{P}<0,05)$} \\
\hline $\begin{array}{l}\text { Número de } \\
\text { espécies em } \\
\text { comum }\end{array}$ & \multicolumn{2}{|c|}{10} & \multicolumn{2}{|l|}{10} \\
\hline $\begin{array}{l}\text { Similaridade } \\
\text { Sorensen }\end{array}$ & \multicolumn{2}{|c|}{0,43} & \multicolumn{2}{|c|}{0,42} \\
\hline $\begin{array}{l}\text { Porcentagem de } \\
\text { similaridade }\end{array}$ & \multicolumn{2}{|c|}{42,4} & \multicolumn{2}{|c|}{26,2} \\
\hline
\end{tabular}

\section{Discussão}

Após dez anos, a área avaliada mostra progresso na recomposição da vegetação com grau de cobertura superior (topo) ou similar (declive) às áreas controle. Houve um incremento na riqueza de espécies nas áreas em recuperação, uma vez que o número de espécies semeadas e plantadas foi em torno de 15 (Prudencio, 1999b). No entanto, a diversidade ecológica ainda é menor nas áreas restauradas e são baixos os índices de similaridade. A baixa semelhança na composição florística das áreas restauradas e controle pode decorrer de pelo menos dois fatores: das mudas introduzidas e do estágio sucessional mais inicial em que as áreas restauradas se encontram.

Quanto ao efeito de mudas, essas geraram maiores diferenças entre as áreas de topo, pois dentre as 11 espécies introduzidas por muda de viveiro, sete estabeleceram-se no topo e apenas três no declive. Destas, apenas uma espécie ocorreu em área restaurada e área controle. As demais ocorreram apenas nos trechos revegetados, reduzindo a similaridade entre os trechos restaurados e os controles.
Das 11 espécies introduzidas por mudas, apenas Eugenia umbelliflora, Myrsine parvifolia e Gaylussacia brasiliensis não sobreviveram, refletindo um bom sucesso de estabelecimento por mudas. Zamith e Scarano (2006) sugerem que o plantio direto de mudas é a melhor estratégia para a restauração de ambientes de restinga, uma vez que o estabelecimento de plântulas a partir de sementes é difícil no substrato arenoso, pobre em nutrientes, com alta insolação e baixa retenção hídrica. No entanto, também houve sucesso de estabelecimento de espécies que foram semeadas diretamente, como Panicum racemosum e Dodonaea viscosa, e daquelas transplantadas de áreas adjacentes, como Diodia radula e Senecio platensis, reforçando a estratégia adotada em demais projetos de restauração que promovem tanto o aporte de sementes como o plantio por mudas (Miranda et al. 1997; Bechara, 2006).

As espécies introduzidas por semeadura direta e transposição de mudas contribuíram para a similaridade entre os trechos restaurados e as áreas controle: destas, $D$. viscosa e $D$. radula ocorreram em todas as áreas avaliadas; $S$. platensis e $P$. racemosum ocorreram na área de topo restaurada e controle. Apesar de P. racemosum ser referida como uma espécie de baixo estabelecimento por plântulas e de baixa viabilidade de sementes no solo (Cordazzo e Davy, 1997), esta teve germinação e estabelecimento eficazes. Panicum racemosum apresenta importantes características ao processo de recuperação de dunas, como alta propagação vegetativa (Cordazzo e Davy, 1999) e longos rizomas que formam uma malha muito rica para a fixação das dunas (Cordazzo e Seeliger, 1988).

Quanto ao desenvolvimento estrutural da vegetação, a área de topo em recomposição, assim como a área de topo controle, apresenta uma baixa cobertura vegetal, com predomínio de espécies herbáceas/subarbustivas. Dentre as espécies encontradas neste trecho em recuperação há várias citadas como elementos da flora herbácea/subarbustiva de dunas, dentre elas $P$. racemosum, D. viscosa e S. platensis (Falkenberg, 1999), que mostraram os maiores valores de cobertura. Esta área apresenta uma fisionomia como aquela onde a duna não foi alterada, onde $P$. racemosum e $S$. platensis também figuram entre as espécies de maior cobertura. $\mathrm{Na}$ área de topo em recuperação, é possível também detectar a 
presença de elementos mais característicos de restinga arbustiva e arbórea (Falkenberg, 1999), como Alchornea triplinervia, com alto valor de cobertura, e também $C$. brasiliense, Eugenia catharinae, Guapira opposita, Gomidesia palustris, L. brasiliensis, P. cattleyanum e $S$. terebinthifolius. Com exceção de A. triplinervia, E. catharinae e Guapira opposita as demais espécies tiveram introdução de mudas na área.

A área em declive em restauração foi caracterizada por uma fisionomia de restinga arbustiva, com dominância de D. viscosa. Esta espécie, que ocorre em formações herbáceas/subarbustiva e arbustivas de restinga, é também característica de estágio médio de regeneração de restinga arbustiva (Falkenberg, 1999). $\mathrm{O}$ trecho em restauração apresentou pouca variedade de espécies arbustivas em relação à área controle, havendo expressiva cobertura de gramíneas ruderais como M. minutiflora e Urochloa sp. e presença de outras espécies exóticas como Furcraea foetida e Pinus sp. Dos elementos característicos de restinga arbustiva e arbórea (Falkenberg, 1999), estão A triplinervia, L. brasiliensis, O. pulchella e $P$. cattleyanum.

Neste projeto, houve o plantio de mudas de I. uruguensis, espécie não ocorrente em restinga. Segundo Burkart (1979), na mata pluvial da encosta atlântica, a espécie ocorre em solos muito úmidos, nas associações do secundário. Sua introdução foi feita pela disponibilidade de mudas nos viveiros e pelo rápido crescimento, característica que poderia auxiliar a fixação do sedimento (M. Prudencio, comunicação pessoal). Porém, é preciso tomar certos cuidados na escolha das espécies para que sejam preferencialmente selecionadas espécies nativas, naturais do local que se deseja regenerar.

A presença de lixo e trilhas na área em recuperação poderia ser amenizada ou até evitada, se houvesse sinalização e orientação aos transeuntes, gerando assim um efetivo processo de sucessão, sem impactos e retrocessos. Estes podem ser demonstrados pela mobilidade da duna, medida pela estaca II da área em declive em recuperação, pois esta se situava próxima a uma trilha e apresentou a maior movimentação de areia. Também se faz necessária uma fiscalização mais efetiva pelo órgão público responsável, neste caso, como o Parque é municipal, pela FLORAM.
As propostas para recuperação ambiental estão passando por um período de inovação e geração de novas técnicas. Entretanto há carência de informações dos resultados de tantos trabalhos que foram e estão sendo feitos, que poderiam refinar cada vez mais as metodologias aplicadas, para a obtenção de processos de sucessão mais próximos aos naturais.

\section{Referências}

Bechara, F. C. 2003. Restauração ecológica de restingas contaminadas por Pinus no Parque Florestal do Rio Vermelho, Florianópolis, SC. Dissertação de Mestrado, Universidade Federal de Santa Catarina, Brasil, 125pp.

Bechara, F. C. 2006. Unidades demonstrativas de restauração ecológica através de técnicas nucleadoras: Floresta Estacional Semidecidual, Cerrado e Restinga. Tese de Doutorado, Universidade de São Paulo, Brasil, 191pp.

Begon, M.; Harper, J. L.; Townsend C. R. 1986. Ecology, individuals, populations and communities. $1^{\text {st }} \mathrm{ed}$. Blackwell Scientific Publications, Oxford, UK, 876pp.

Bresolin, A. 1979. Flora da restinga da Ilha de Santa Catarina. Insula, 10: 1-54.

Brower, J. E.; Zar, J. H.; von Ende, C. N. 1998. Field and laboratory methods for general ecology. $4^{\text {th }} \mathrm{ed}$. WCB/McGrawHill, Boston, USA, 273pp.

Burkart, A. 1979. Leguminosas Mimosoideas: I Parte. In: Reitz, P. R. (Ed.). Flora Ilustrada Catarinense. Herbário Barbosa Rodrigues, Itajaí, Brasil, p.1-304.

CECCA - Centro de Estudos Cultura e Cidadania. 1997. Unidades de conservação e áreas protegidas da Ilha de Santa Catarina: Caracterização e legislação. Editora Insular, Florianópolis, Brasil, 160pp.

Cordazzo, C. V.; Davy, A. J. 1997. Effects of temperature and light on seed germination in the dune-building grass Panicum racemosum Spreng. Atlântica, 19: 87-97.

Cordazzo, C. V.; Davy, A. J. 1999. Vegetative regeneration of Panicum racemosum from rhizome fragments on southern Brazilian coastal dunes. Journal of Coastal Research, 15: 520-525.

Cordazzo, C. V.; Paiva, J. B.; Seeliger, U. 2006. Guia ilustrado: plantas das dunas da costa sudoeste atlântica. União SulAmericana de Estudos da Biodiversidade, Pelotas, Brasil, 107pp.

Cordazzo, C. V.; Seeliger, U. 1988. Guia ilustrado da vegetação costeira no extremo sul do Brasil. Editora da Fundação Universidade do Rio Grande, Rio Grande, Brasil, 275pp.

Costa, C. S. B.; Seeliger, U.; Cordazzo, C. V. 1991. Leaf demography and decline of Panicum racemosum populations in coastal foredunes of southern Brazil. Canadian Journal of Botany, 69: 1593-1599.

Cunha, L. O.; Fontes, M. A. L.; Oliveira A. D.; Filho A. T. O. 2003. Análise multivariada da vegetação como ferramenta para avaliar a reabilitação de dunas litorâneas mineradas em Mataraca, Paraíba, Brasil. Sociedade de Investigações Florestais, 27: 503-504. 
Dewhurst, D. 2001. Coastal dunes: Dune protection and improvement manual for the Texas Gulf Coast. $2^{\text {nd }}$ ed. Texas General Land Office, Vernon, USA, 28pp.

Falkenberg, D. B. 1999. Aspectos da flora e da vegetação secundária da restinga de Santa Catarina, sul do Brasil. Insula, 28: 1-30.

Freire, M. S. B. 1983. Experiência de revegetação nas dunas costeiras de Natal. Brasil Florestal, 53: 35-42.

Gomes-Neto, A.; Bosa, P.; Emilio, T. C.; Cunha, S. R. 2004. Plantio de Ipomoea pes-caprae nas dunas da Praia Brava (Itajaí, SC): Comparação de duas técnicas. Notas Técnicas da FACIMAR, 8: 33-38.

Greig-Smith, P. 1983. Quantitative plant ecology. $3^{\text {rd }}$ ed. Blackwell Scientific Publications, Oxford, UK, 359pp.

Krebs, C. J. 1999. Ecological methodology. $2^{\text {nd }}$ ed. Addison Wesley Longman, Menlo Park, USA, 620pp.

Miranda, R. F.; Barroso, D. G.; Marinho, C. S.; Carvalho, D. A. 1997. Estudo sobre a vegetação em dunas de rejeito de mineração no litoral norte do estado da Paraíba. Revista Árvore, 21: 345-351.

Nordstrom, K. F. 2000. Beaches and dunes of developed coasts. Cambridge University Press, Cambridge, UK, 338pp.

Prudencio, M. 1999a. Projeto de recomposição da vegetação fixadora de duna na região limítrofe norte do Parque Municipal das Dunas da Lagoa da Conceição. Projeto técnico, Florianópolis, Brasil, 8pp.
Prudencio, M. 1999b. Projeto de recomposição da vegetação fixadora de duna na região limítrofe norte do Parque Municipal das Dunas da Lagoa da Conceição. Relatório técnico de atividades e vistorias, Florianópolis, Brasil, 9pp.

Reis, A.; Bechara, F. C.; Espindola, M. B.; Vieira, N. K.; Souza, L. L. 2003. Restauração de áreas degradadas: A nucleação como base para incrementar os processos sucessionais. Natureza \& Conservação, 1 (1): 28-36.

Santos, C. R.; Horn-Filho, N. O.; Castellani, T. T. 1997. Estudo geológico e ambiental da praia da Joaquina (SC). Oecologia Brasiliensis, 3: 259-270.

Scherer-Widmer, M. 2001 Dune revegetation with native species of restinga on the southern coast of Brazil. Journal of Coastal Research - Special Issue, 34: 593-596.

Seeliger, U. 2003. Response of southern Brazilian coastal foredunes to natural and human-induced disturbance. Journal of Coastal Research - Special Issue, 35: 51-55.

Seeliger, U.; Cordazzo, C. V.; Oliveira, C. P. L.; Seeliger, M. 2000. Long-term changes of coastal foredunes in the southwest Atlantic. Journal of Coastal Research, 16: 1068-1072.

Zamith, L. R.; Scarano, F. R. 2006. Restoration of a Restinga sandy coastal plain in Brazil: Survival and growth of planted wood species. Restoration Ecology, 14: 87-88.

Zar, J. H. 1999. Biostatistical analysis. $4^{\text {th }}$ ed. Prentice Hall, Upper Saddle River, USA, 663pp. 